\title{
ESTUDO DO COMPORTAMENTO DE COMPRA DO FREQUENTADOR DE SHOPPING CENTERS NA CIDADE DE SÃo PAULO
}

\author{
A study of the shopping behavior \\ of shopping center visitors \\ in the city of São Paulo
}

Envio 30.10.08 / Aceite 01.12.08

\author{
Patricia de Salles Vance ${ }^{1}$ \\ Prof. Dr. Cláudio Felisoni de Angelo ${ }^{2}$ \\ Prof. Dr. Nuno Manoel Martins Dias Fouto ${ }^{3}$
}

\section{Resumo}

Com a redução de tempo disponível das pessoas e a crescente insegurança dos grandes centros urbanos no país, o shopping center oferece aos consumidores um local de compra em que várias necessidades podem ser atendidas em um mesmo lugar. O objetivo deste artigo foi compreender melhor o comportamento dos frequentadores de shopping centers da cidade de São Paulo, investigando a motivação de ida a esses centros comercias. Trata-se, evidentemente, de uma informação fundamental para a definição das ofertas de serviços nesses locais. Ao todo, foram entrevistados 500 consumidores da cidade de São Paulo, utilizando-se

\footnotetext{
1Doutoranda em Administração de Empresas da FEA/USP. E-mail: psvance@usp.br

${ }^{2}$ Professor titular da FEA/USP. Universidade de São Paulo, Faculdade de Economia Administração e Contabilidade, Departamento de Administração. Avenida Prof. Luciano Gualberto 908 - Sala G121 - Cidade Universitária 05508900 - Sao Paulo, SP - Brasil. E-mail: cfa@usp.br

${ }^{3}$ Professor da FEA/USP. Universidade de São Paulo, Faculdade de Economia Administração e Contabilidade, Departamento de Administração. Avenida Prof. Luciano Gualberto 908 - Sala G121. Cidade Universitária 05508900 - Sao Paulo, SP - Brasil. E-mail: nfouto@usp.br
} 
um questionário com perguntas fechadas. Para a análise dos dados, foi aplicada a técnica de análise de correspondência (ANACOR), com o propósito de tratar as variáveis qualitativas representativas das preferências dos indivíduos entrevistados.

Palavras-chave: Shopping Center; Varejo; Comportamento do Consumidor

\begin{abstract}
With the reduction of time and the increasing insecurity of people in major urban centers in the country, the mall offers consumers a shopping location where various needs can be met in one place. This paper's main objective was to better understand the behavior of visitors to shopping malls in the city of São Paulo, investigating the motivation for going to these malls. This is an essential information for defining the service offerings at these locations. In all, 500 consumers were interviewed in the city of São Paulo, using a questionnaire with closed questions. As data analysis technique was applied the analysis of correspondence (ANACOR), with the aim of addressing the qualitative variables representing the preferences of individuals interviewed.
\end{abstract}

Keywords: Shopping Center; Retail; Consumer Behavior.

\title{
1 Introdução
}

Em um ambiente dinâmico e altamente competitivo, é fundamental que o varejista não só conheça o seu cliente, como também compreenda o seu comportamento de compra. Assim, os varejistas, cada vez mais, adotam estratégias de multicanal. Além das lojas tradicionais, há muitas outras opções, por exemplo: comércio eletrônico, da venda direta etc.

Mesmo ao optar pela abertura de uma nova loja, os varejistas dispõem de várias alternativas, entre as quais o shopping center, que combina diferentes tipos de varejo sob o mesmo teto. Segundo dados da ABRASCE (2006), ao final de 2005, eram 263 shopping centers no País, com faturamento de R $\$ 40$ bilhões, representando $18 \%$ do varejo nacional (excluído o setor automotivo). Somente na cidade de São Paulo estavam localizados 41 desses empreendimentos, representando $23 \%$ da ABL (área bruta locável) do país.

Com a redução de tempo disponível das pessoas e a crescente insegurança dos grandes centros urbanos, o shopping center oferece aos consumidores um local de compra em que várias necessidades podem ser atendidas em um mesmo lugar. Esses empreendimentos evoluíram ao longo dos anos, colocando à disposição do consumidor opções de entretenimento e de serviços, tais como: restaurantes, cinemas, teatros, bancos, salões de beleza, supermercados, academias de ginástica etc.

A composição do mix de lojas difere entre empreendimentos, em alguns casos de forma marcante. A Alshop (2006), no 3o Anuário Brasileiro de Shoppings, classifica esses empreendimentos em cinco categorias. Mesmo dentro de uma mesma categoria, é possível identificar estratégias de posicionamento diferenciadas entre os shoppings. Considerando os empreendimentos tradicionais, verifica-se, por exemplo, que os Shoppings Iguatemi e Higienópolis estão voltados para os consumidores da classe de renda alta, os Shoppings Tatuapé e Taboão, por sua vez, são direcionados para um público de renda mais baixa. 
Nesse contexto, este estudo propõe-se a investigar uma dimensão básica das estratégias de posicionamento: os consumidores (MASON, MAYER e WILKINSON, 1993). Pretende-se, portanto, compreender melhor o comportamento dos frequentadores de shopping centers da cidade de São Paulo, mais especificamente, a motivação de ida a esses locais.

Este trabalho está organizado em quatro seções, nas quais são abordados: o método de pesquisa; a revisão da literatura relacionada ao comportamento de compra do consumidor e ao setor de shopping center; a apresentação e análise dos resultados e, finalmente, na última seção, são apontadas as conclusões gerais, as limitações e assinaladas algumas possíveis extensões.

\section{Método de pesquisa}

A pesquisa foi estruturada em duas etapas. Em um primeiro momento, efetuouse uma revisão da literatura sobre o comportamento de compra do consumidor e sobre o desenvolvimento do setor de shopping center no país.

Na segunda etapa, foram entrevistados 500 consumidores da cidade de São Paulo, utilizando-se um questionário com perguntas fechadas. O questionário foi previamente submetido a pré-teste com 40 consumidores. O resultado dessas tabulações forneceu os elementos para se estruturar o instrumento de pesquisa definitivo.

O universo para o qual a investigação foi delineada constituiu-se pelos consumidores adultos da cidade de São Paulo. Como uma pesquisa de caráter censitário requer um volume de recursos excessivamente elevado, optou-se pela utilização de uma amostra. Como não se conhecia a priori a dispersão da população, admitiu-se o pior caso possível para o dimensionamento da amostra, que é o de $50 \%$ de respostas positivas e $50 \%$ de respostas negativas. Adotando-se um nível de acerto de 95,5\% no estabelecimento dos intervalos de confiança e um erro máximo 5\%, chega-se a um tamanho de amostra de 400 pessoas (nesta pesquisa foram entrevistados 500 consumidores, o que representa um número a favor da segurança). Sendo a amostra muito menor do que a população, não foi necessário utilizar o fator de correção para populações finitas.

As entrevistas foram realizadas na rua, em locais pré-definidos, a partir de critérios de estratificação por região da cidade, por faixa de renda e por sexo. Com base em dados censitários do IBGE, a amostra foi dividida igualmente entre homens e mulheres. Quase a metade da amostra $(48,2 \%)$ está na faixa etária entre 25 e 40 anos. No que diz respeito à renda, pode-se dizer que 91,6\% dos entrevistados encontram-se na faixa de zero a 15 salários mínimos.

Com vistas a especificar uma amostra que considerasse regiões com diferentes perfis socioeconômicos da cidade de São Paulo (ATLAS AMBIENTAL DO MUNICÍPIO DE SÃO PAULO, 2006), foi adotado o critério de amostragem por cotas, mesmo reconhecendo que este critério não é rigorosamente probabilístico. Desse modo, cinco grupos de distritos foram considerados. A divisão dos 96 distritos em grupos foi obtida a partir da aplicação da técnica estatística de Análise Fatorial, com base nas seguintes variáveis: renda familiar, quota residencial, nível de escolaridade, perfil etário, mortalidade infantil, crescimento populacional, índice de criminalidade, população favelada e densidade populacional (vide anexo).

Os grupos foram definidos com base no índice do fator principal, incluindo o Grupo 1, os distritos com os menores valores para o índice e, no outro extremo, o Grupo 5, englobando aqueles com os maiores valores apurados. 
Ao todo foram entrevistadas pessoas em 22 distritos. Com isso, a amostra considerada apresentou a seguinte composição:

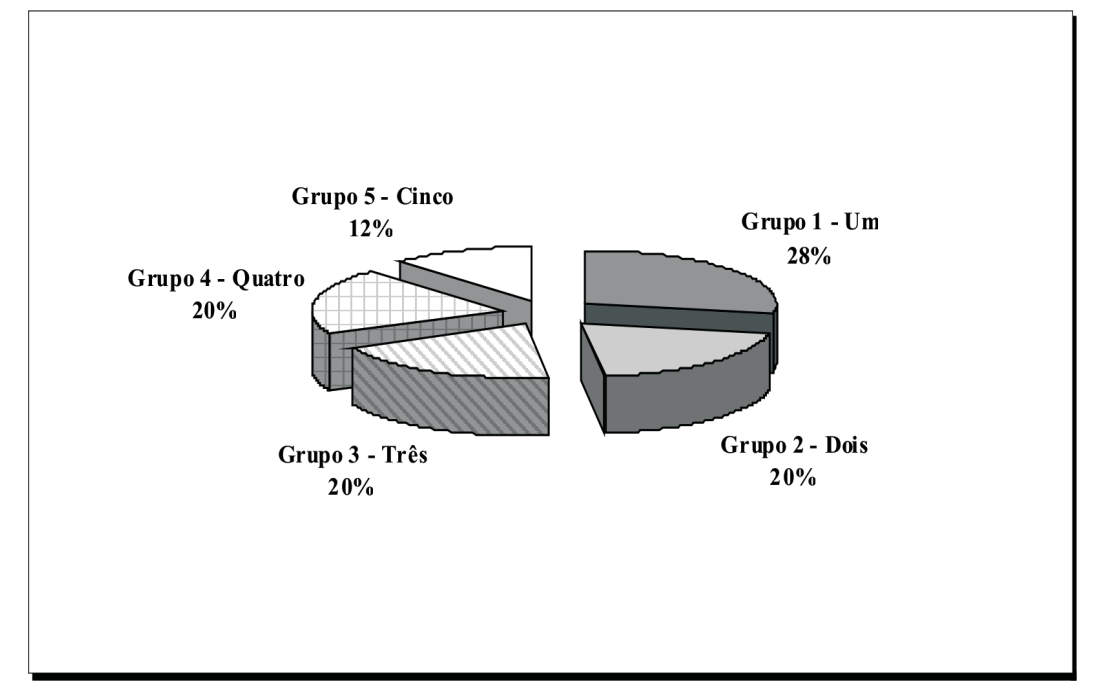

Figura 1 - Distribuição da amostra por grupo socioeconômico.

Tendo a pesquisa como principal foco a compreensão da motivação de ida ao shopping, sobre esses dados foi aplicada a técnica de análise de correspondência (ANACOR), com o propósito de tratar as variáveis qualitativas representativas das preferências dos indivíduos entrevistados.

Essa técnica analisa a estrutura das interdependências entre variáveis, a partir de correlações, e identifica dimensões latentes comuns, denominadas de fatores. As duas principais aplicações da análise fatorial são o resumo e a redução de variáveis (HAIR et al., 2005).

A análise de correspondência é uma técnica de interdependência que atua na redução de dimensões e retrata os resultados por meio de mapas perceptuais (HAIR et al., 2005). Esses mapas permitem uma visualização fácil das associações entre variáveis. O procedimento adotado para padronização foi a estatística Qui-quadrado, e o método de normalização escolhido foi o simétrico.

\section{Revisão bibliográfica}

Uma das grandes questões estratégicas do varejo é a localização de lojas. Os shopping centers representam um empreendimento imobiliário, cuja principal receita provém do pagamento do aluguel das lojas (BNDES, 1996; BRANCO et al., 2007).

Os shopping centers reúnem, sob o mesmo teto, diferentes lojas que apresentam sinergia entre si, tornando esses locais atraentes para os consumidores (LEVY e WEITZ, 2000). Segundo Kotler e Armstrong (1999, p. 301), os shopping centers correspondem a "agrupamento planejado de varejistas desenvolvido, possuído e administrado como uma unidade".

Esse tipo de empreendimento teve início nos EUA na década de 1950. No Brasil, o primeiro shopping foi aberto na cidade de São Paulo em 1966. Os shoppings evoluíram e ocupam, hoje, um espaço social importante nas cidades brasileiras, modernizando o conceito de praça pública (IHU, 2005).

Além das lojas tradicionais, os shopping centers reúnem também praça de alimentação, que podem incluir desde renomadas cadeias de fast-food até sofisticados restaurantes, cinemas, 
teatros e área de lazer para crianças. Em alguns shoppings, são realizados eventos culturais ou comerciais em áreas internas e externas não ocupadas (MOACYR, 1997)

Existem vários tipos de shopping centers, como, por exemplo, tradicionais, outlets, temáticos e festival mall. Os tradicionais têm um sortimento de estabelecimentos que combina lojas-satélite e lojas-ancôra, que interam redes varejistas de renome e atraem um grande fluxo de pessoas. Os outlets são compostos apenas por lojas de fábrica ou off-price, cuja estratégia baseia-se no oferecimento de preços baixos aos consumidores. O público-alvo desse tipo de empreendimento são as classes de renda mais baixa. Os temáticos ou especializados reúnem varejistas de apenas um segmento, como, por exemplo, moda ou decoração. Os festival malls dedicam-se exclusivamente a atividades culturais e de entretenimento, com foco, principalmente, às classes de renda mais altas (MOACYR, 1997; ALSHOP, 2006; LOJISTAS.NET, 2006)

O setor de Shopping Centers no país tem se desenvolvido ao longo dos anos. Segundo a ABRASCE (2006), ao final de 2005, eram 263 empreendimentos, 43\% deles localizados no interior, contra apenas 15\%, em 1983. Ao todo incluíam "41 mil lojas-satélite, 946 lojas-âncora e 1.115 salas de cinema e teatro" e 488 mil empregos diretos.

Entretanto, os dados do Censo Brasileiro de Shopping Centers (2006) da Alshop (Associação Brasileira de Lojistas de Shopping) são ainda maiores. De acordo com os dados da Alshop, o faturamento do setor, em 2005, totalizou R\$ 59,3 bilhões, representando 26\% do varejo brasileiro. Essa associação identificou 601 shopping centers concentrados na região Sudeste do país, representando $54,25 \%$ do total.

O shopping center é uma característica marcante da modernidade. No Brasil, esse modelo, como se demonstrou, está em franca expansão. É nesse cenário que o presente artigo procura examinar o comportamento de compra dos consumidores.

Um dos pilares da estratégia do varejista é a satisfação das necessidades de seu cliente (LEVY e WEITZ, 2000). Para tanto, é essencial que o varejista conheça seu cliente e o seu comportamento de compra.

Para analisar o processo de compra, Levy e Weitz (2000) adotam um modelo que considera tanto a escolha do varejista quanto a aquisição do produto ou serviço. O processo de compra é composto de quatro estágios básicos: reconhecimento da necessidade, busca de informações, avaliação e escolha. Neste estudo, o interesse limita-se à escolha do shopping center e ao comportamento de comprador dentro desses empreendimentos, portanto, à aplicação de cada etapa até a seleção do shopping center e da loja dentro dele.

Aos varejistas interessa não apenas saber o que os consumidores pretendem comprar, mas onde eles pretendem realizar suas compras (BERMAN e EVANS, 1998). Enquanto o fabricante tem interesse que o consumidor adquira sua marca, o varejista deseja que o indivíduo escolha a sua loja para a realização da compra. Esses autores adotam um modelo do processo de compra em seis estágios (estímulo, reconhecimento do problema, busca de informação, avaliação de alternativas, compra e comportamento pós-compra), nos quais não há uma separação clara entre a escolha da loja e do produto.

Samli (1989) adota um modelo com três etapas (pré-compra, compra e pós-compra), composto de cinco fatores: motivação de compra, características do comprador, compra planejada ou não-planejada, modelo de comportamento do consumidor do varejo e atividades pós-compra. Esse modelo de comportamento do consumidor de varejo, por sua vez, inclui sete fases: percepção, reconhecimento do problema, busca de informações, processamento de informações, seleção da loja, compra e pós-compra. Desse modo, apresentando semelhanças ao modelo utilizado por Berman e Evans (1998), exceto por explicitar uma etapa de escolha da loja. 
Para o estudo em questão, foi adotado o modelo proposto por Levy e Weitz (2000), haja vista o interesse em se concentrar na escolha do local de compra.

Assim, é fundamental primeiro compreender as necessidades de compra dos indivíduos, que podem ser classificadas em pessoais ou sociais (MASON, MAYER e WILKINSON, 1993; ENGEL, BLACKWELL e MINIARD, 2000). As motivações pessoais incluem: lazer, quebra da rotina, atividade física (como passear pelo shopping center), estímulo sensorial, conhecimento de novas tendências, representação de um papel na sociedade (ex.: compra de presente no Dia das Mães). Já as motivações sociais envolvem a necessidade de interação com um determinado grupo social, como, por exemplo: convívio com pessoas com interesses similares, busca de grupos de referência, status ou autoridade (ex.: compra de um produto de luxo), prazer de pechinchar etc. Em estudo conduzido por Martin e Turley (2004), foi identificado que as motivações sociais dos consumidores influenciava o modo como estes percebiam o shopping center.

A segunda etapa do processo de compra é o de busca de informações. Este momento envolve uma busca interna e externa de informações. A busca interna refere-se à memória do indivíduo e pode ser suficiente se a experiência de compra anterior for satisfatória. No entanto, os indivíduos podem recorrer a informações externas, como: propaganda na mídia, recomendações de amigos etc., para escolher o local de compra.

Com as informações, o comprador avalia o local onde realizará a compra. Levy e Weitz (2000) apresentam o modelo de multi-atributo utilizado por Durand e Dreves (apud LEVY e WEITZ, 2000) aplicado ao varejo. Esse modelo baseia-se no desempenho do varejista em diferentes atributos e também na importância relativa de cada atributo para o comprador. Diferentes estudos tem sido realizados com vistas a identificar os atributos considerados nesta etapa do processo de compra. Sit, Merrilees e Birch (2003) analisam sete categorias de atributos utilizados pelas pessoas para a escolha do shopping center (sortimento, acessibilidade, serviço, atmosfera, entretenimento, alimentação e segurança). Kotler (1974) apresenta um estudo sobre o papel da atmosfera no varejo. Como atributos da loja, Samli (1989) cita: arrumação, reputação, atendimento, exposição dos produtos, promoções, marcas, informação do comprador. Bell, Ho e Tang (1998) propõem um modelo que analisa os custos fixos e variáveis de escolha do local de compra, incluindo atributos como o tempo de deslocamento. Ao investigar situações de compra no varejo, Stoltman, Morgan e Anglin (1999) selecionaram seis atributos: disponibilidade do produto, atmosfera de loja, atendimento, tumulto (crowding), disponibilidade de estacionamento, condições de tempo. Wong, Lu e Yuan (2001) adotam um modelo de 21 atributos para estudar a atratividade do shopping center para o consumidor chinês. Lee, Ibrahim e Hsueh-Shan (2005), Baker et al. (2002) e Yavas (2003) também utilizam modelos de multiatributos para entender a escolha de uma loja ou de um shopping pelo cliente.

Além disso, o comportamento das pessoas também depende do tipo de situação de compra envolvido. Levy e Weitz (2000, p. 120) classificam os tipos de decisões de compras em: "solução extensa de problemas, solução limitada de problemas e tomada de decisões habitual". A solução extensa de problemas envolve decisões que demandam tempo e esforço dos clientes nas análises das alternativas. Os riscos envolvidos podem ser tanto financeiros, quanto físicos ou mesmo sociais. A solução limitada de problemas requer um envolvimento menor do cliente por representar um risco moderado e um comprometimento menor em termos de tempo e risco. A tendência em uma situação deste tipo é o cliente basear a decisão em sua experiência prévia, optando por direcionar sua compra para varejistas conhecidos. Os autores classificam nessa categoria as compras por impulso, em que um cliente decide adquirir o produto no momento em que o vê. A tomada de decisões habitual refere-se, por sua vez, 
à repetição de compras anteriores, em que praticamente não ocorre um esforço consciente. Essa mesma classificação também é utilizada por Berman e Evans (1998). Belk (in NICHOLLS, 1997) argumenta que fatores como as circunsâncias e o ambiente no momento da compra influenciam o comportamento de compra das pessoas, de modo que aspectos como a situação de compra, a atmosfera da loja, a companhia no momento da compra, a disposição física, o humor, são todos fatores que afetam o processo de compra. Nicholls (1997) realiza um estudo para compreender o comportamento de compra dos hispânicos, analisando aspectos como a duração da compra e a ida ao shopping acompanhado.

Em casos de urgência, um shopping pode ser considerado o local ideal por seu sortimento ou inconveniente se a compra pode ser realizada mais rapidamente em uma loja de rua (ex.: a compra de um vinho para um jantar na casa de um amigo). Ao mesmo tempo, o amplo sortimento de lojas e prestadores de serviços instalados em um shopping center possibilita que, em um mesmo momento, haja clientes vivenciando situações de compra absolutamente distintas. Enquanto um cliente precisa decidir sobre a compra de um televisor, um procura uma roupa nova, um escolhe um restaurante para jantar, um está indo ao cinema e um foi apenas fazer compras de supermercado.

A quarta etapa é a da escolha de alternativas. Na prática, os consumidores, em geral, não adotam um modelo formal de multiatributos. No entanto, o mesmo atua como referencial para que os varejistas possam compreender melhor o comportamento de compra dos clientes. Implicitamente, as pessoas realizam comparações entre as alternativas e optam por aquela mais adequada para suprir a sua necessidade.

Um último aspecto é a satisfação do cliente do shopping center. Este aspecto está relacionado ao estágio pós-compra. Mason e Burns (1998) observam que o nível de satisfação do cliente é fator-chave para o estabelecimento de um relacionamento de longo prazo entre o varejista e o cliente. Para o gestor do shopping center e para os varejistas instalados dentro desse empreendimento, a compreensão do comportamento e da satisfação do cliente é estratégica não só por causa da repetição de visitas, mas também pela influência que esse indivíduo pode ter na formação da imagem do negócio junto a outras pessoas com as quais convive.

\section{Resultados}

Foi investigada a primeira etapa do processo de compra (LEVY e WEITZ, 2000), a de reconhecimento da necessidade. Houve, portanto, o interesse em identificar com que frequência os entrevistados iam ao shopping center, quando essa visita em geral ocorria, qual a motivação da visita e se esta era diferente durante a semana ou nos finais de semana.

Pouco mais da metade dos entrevistados $(52,6 \%)$ informaram que vão aos shopping centers pelo menos uma vez por semana, enquanto $3,6 \%$ responderam que raramente frequentam shopping centers.

A classificação desses dados, considerando como critérios os grupos, a idade dos respondentes e a correspondente faixa de renda familiar, possibilitou a identificação de diferenças na frequência de ida ao shopping center dos diferentes segmentos entrevistados (Tabela 1). Enquanto todos respondentes do Grupo I informaram que vão ao shopping center pelo menos uma vez por semana, 64\% dos respondentes do Grupo II visitam esses locais no máximo uma vez por mês. Esse resultado pode ser um indício de uma carência desse tipo de local nos distritos municipais que compõem este grupo ou mesmo de uma inadequação dos empreendimentos atuais nessa mesma região às necessidades da população local. 
Tabela 1 - Frequência de ida ao shopping center por grupo

\begin{tabular}{lrrrrr}
\hline & \multicolumn{1}{c}{$\begin{array}{c}\text { Pelo } \\
\text { menos } 1\end{array}$} & & & & \\
vez na & A cada 15 & & Menos de 1 & \\
Grupo & dias & Mensalmente vez por mês & Total \\
\hline 1 & $100 \%$ & $0 \%$ & $0 \%$ & $0 \%$ & $100 \%$ \\
2 & $10 \%$ & $27 \%$ & $56 \%$ & $7 \%$ & $100 \%$ \\
3 & $57 \%$ & $19 \%$ & $17 \%$ & $7 \%$ & $100 \%$ \\
4 & $36 \%$ & $25 \%$ & $35 \%$ & $4 \%$ & $100 \%$ \\
5 & $33 \%$ & $38 \%$ & $28 \%$ & $0 \%$ & $100 \%$ \\
Total & $53 \%$ & $19 \%$ & $25 \%$ & $4 \%$ & $100 \%$ \\
\hline
\end{tabular}

Considerando a renda familiar segmentada em quatro faixas distintas, verificou-se, na primeira faixa (até três salários mínimos), que 59\% dos entrevistados vão ao shopping pelo menos uma vez a cada quinze dias, enquanto este percentual é superior a $70 \%$ para as demais faixas de renda familiar (Tabela 2).

Tabela 2 - Frequência de ida ao shopping center por renda familiar

\begin{tabular}{|c|c|c|c|c|c|}
\hline Grupo & $\begin{array}{c}\text { Pelo } \\
\text { menos } 1 \\
\text { vez na } \\
\text { semana }\end{array}$ & $\begin{array}{l}\text { A cada } 15 \\
\text { dias }\end{array}$ & Mensalmente & $\begin{array}{l}\text { Menos de } 1 \\
\text { vez por mês }\end{array}$ & Total \\
\hline 1 & $100 \%$ & $0 \%$ & $0 \%$ & $0 \%$ & $100 \%$ \\
\hline 2 & $10 \%$ & $27 \%$ & $56 \%$ & $7 \%$ & $100 \%$ \\
\hline 3 & $57 \%$ & $19 \%$ & $17 \%$ & $7 \%$ & $100 \%$ \\
\hline 4 & $36 \%$ & $25 \%$ & $35 \%$ & $4 \%$ & $100 \%$ \\
\hline 5 & $33 \%$ & $38 \%$ & $28 \%$ & $0 \%$ & $100 \%$ \\
\hline Total & $53 \%$ & $19 \%$ & $25 \%$ & $4 \%$ & $100 \%$ \\
\hline
\end{tabular}

A análise dos dados por faixa etária não revelou diferenças importantes entre os grupos em todos os segmentos, pelo menos 70\% dos integrantes informaram que vão ao shopping center pelo menos uma vez a cada 15 dias (Tabela 3). Entretanto, enquanto 100\% dos respondentes 
do grupo I com até 24 anos de idade informaram frequentar o shopping center pelo menos uma vez por semana, quase $50 \%$ dos entrevistados desta mesma faixa etária do grupo II informaram frequentá-lo no máximo uma vez por mês. Esse resultado sinaliza uma diferença relevante no comportamento dos indivíduos entre os grupos de distritos municipais incluídos na amostra.

Tabela 3 - Frequência de ida ao shopping center por idade

\begin{tabular}{|c|c|c|c|c|c|}
\hline & $\begin{array}{c}\text { Pelo } \\
\text { menos } 1 \\
\text { vez na }\end{array}$ & A cada 15 & & Menos de 1 & \\
\hline Idade & semana & dias & Mensalmente & vez por mês & Total \\
\hline até 24 anos & $51 \%$ & $21 \%$ & $24 \%$ & $4 \%$ & $100 \%$ \\
\hline de 24 a 40 anos & $52 \%$ & $20 \%$ & $25 \%$ & $2 \%$ & $100 \%$ \\
\hline de 41 a 60 anos & $56 \%$ & $14 \%$ & $24 \%$ & $6 \%$ & $100 \%$ \\
\hline Total & $53 \%$ & $19 \%$ & $25 \%$ & $4 \%$ & $100 \%$ \\
\hline
\end{tabular}

Enquanto $44,8 \%$ preferem ir ao shopping nos finais de semana, 48,2\% informaram ir tanto nos finais de semana quanto durante a semana. Apenas $60 \%$ dos indivíduos do grupo II e $36 \%$ dos do grupo III responderam que frequentam o shopping nos dias úteis. Para os demais grupos de distritos municipais, 100\% dos entrevistados confirmaram ir ao shopping center durante a semana (de segunda a sexta-feira). Na análise por faixa de renda, 63,1\% dos respondentes com renda familiar até 3 salários mínimos informaram não frequentar o shopping center em dias úteis. Considerando os respondentes por faixa etária, o percentual mais baixo apresentado para esta questão foi entre os indivíduos com até 24 anos (74\%).

Durante a semana, o principal motivo apresentado para ir ao shopping foi almoçar com colegas de trabalho $(24,2 \%)$, seguido de fazer compras $(23,2 \%)$ e de utilizar serviços $(19,2 \%)$. É interessante observar que há uma alteração das necessidades que levam o entrevistado a frequentar o shopping no final de semana, sendo citado: passear (29,2\%), ir aos cinemas (25,0\%) e fazer compras (19,6\%). Os resultados indicam que, para mais da metade dos consumidores, o shopping é um destino de lazer nos finais de semana, enquanto nos dias úteis a necessidade de realização de compras e de uso dos serviços é mais aparente.

Com vistas a identificar se os motivos apresentados eram diferentes entre os grupos de respondentes, foi aplicada a técnica de Análise de Correspondência (Anacor) sobre os dados segmentados por grupo de distrito municipal, renda familiar e faixa etária. Para esta análise, foi considerado apenas o principal motivo citado pelos respondentes para irem ao shopping center.

A análise dos resíduos padronizados permite determinar a caracterização dos diferentes públicos segundo o motivo de ida ao shopping.

Primeiramente, foram analisadas as respostas referentes à frequência dos shopping centers nos dias úteis. Ao todo foram considerados os cinco motivos mais citados, correspondendo a $85,6 \%$ das respostas. De um total de 500 entrevistados, apenas 339 pessoas responderam a esta questão. 
O contingenciamento entre o grupo socioeconômico e o motivo de ida ao shopping nos dias úteis revela que essas variáveis não são independentes ( $x^{2}=150,493 ; p=0,000$ ), ou seja, não se combinam aleatoriamente, o que propicia a aplicação da técnica de análise de correspondência (Tabela 4).

Tabela 4 - Tabela de contingência entre grupo e motivos de ida aos shopping centers durante a semana

\begin{tabular}{l|c|l|c|c|c|c}
\hline Grupo & Cinema & Passeio & $\begin{array}{l}\text { Almoço } \\
\text { colegas } \\
\text { trabalho }\end{array}$ & $\begin{array}{l}\text { Almoço } \\
\text { amigos/famillia }\end{array}$ & Compras & Total \\
\hline Grupo I & 2 & 33 & 73 & 3 & 8 & 119 \\
\hline Grupo II & 9 & 22 & 13 & 1 & 8 & 53 \\
\hline Grupo III & 0 & 1 & 23 & 1 & 0 & 25 \\
\hline Grupo IV & 26 & 33 & 6 & 10 & 14 & 89 \\
\hline Grupo V & 14 & 12 & 6 & 4 & 17 & 53 \\
\hline Total & 51 & 101 & 121 & 19 & 47 & 339 \\
\hline \multicolumn{7}{l}{$X^{2:} 150,493$} \\
\hline
\end{tabular}

O mapa perceptual dos motivos e dos segmentos organizados por grupo de distrito municipal revelou a proximidade do grupo I, principalmente, ao motivo almoço com colegas de trabalho (Figura 2). O grupo II apresenta a maior proximidade com o motivo passeio, enquanto o grupo $\mathrm{V}$, que inclui os distritos com o maior poder aquisitivo, a realização de compras destacase dentre as demais opções.

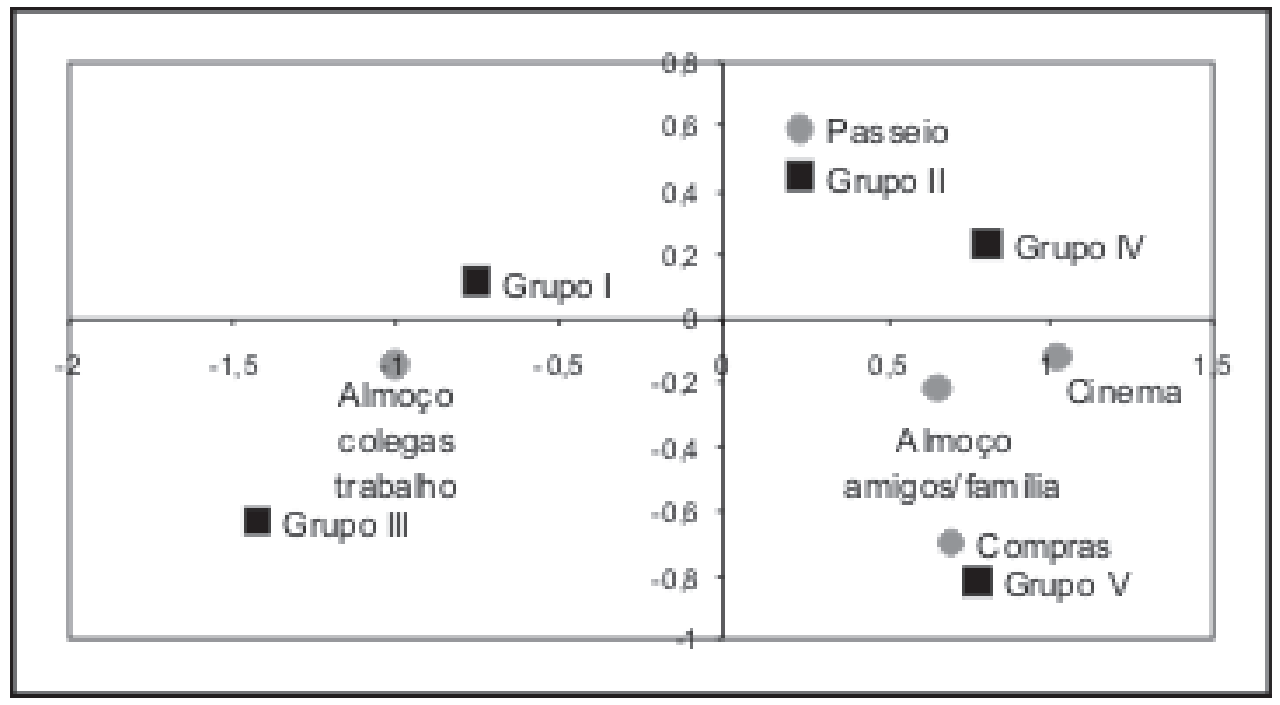

Figura 2 - Motivo para ida ao shopping center nos dias úteis por grupo.

O contingenciamento entre a renda familiar e o motivo de ida ao shopping nos dias úteis indica que essas variáveis não são independentes $\left(x^{2}=36,860 ; p=0,000\right)$, ou seja, não se combinam aleatoriamente, permitindo a aplicação da técnica de análise de correspondência (Tabela 5). 
Tabela 5 - Tabela de contingência entre renda familiar e motivos de ida ao shopping center durante a semana

\begin{tabular}{|c|c|c|c|c|c|c|}
\hline Renda Familiar & Cinema & Passeio & $\begin{array}{l}\text { Almoço colegas } \\
\text { trabalho }\end{array}$ & $\begin{array}{l}\text { Almoço } \\
\text { amigos/família }\end{array}$ & Compras & Total \\
\hline Até 3 s.m. & 13 & 20 & 14 & 5 & 7 & 59 \\
\hline De 3,1 s.m. até 8 s.m. & 19 & 55 & 72 & 7 & 17 & 170 \\
\hline De 8,1 s.m. até 15 s.m. & 10 & 20 & 32 & 2 & 15 & 79 \\
\hline Acima de 15,1 s.m. & 9 & 6 & 3 & 5 & 8 & 31 \\
\hline Total & 51 & 101 & 121 & 19 & 47 & 339 \\
\hline \multicolumn{3}{|c|}{$\chi^{2}: 36,860$} & \multicolumn{2}{|c|}{ GL:12 } & \multicolumn{2}{|c|}{ p: 0,000} \\
\hline
\end{tabular}

Analisando esta mesma questão a partir da renda familiar, verificou-se, no mapa perceptual, a localização dos respondentes com rendimentos até três salários mínimos entre os motivos passeio, almoço ou jantar com amigos ou familiares e cinema (Figura 3). Por outro lado, para os indivíduos com renda familiar entre 8,1 salários mínimos e 15 salários mínimos, destacaram-se os motivos compras e almoço com colegas de trabalho. A citação do motivo compras é mais frequente entre os respondentes com maior faixa de renda, o que pode estar associado a uma menor sensibilidade a preço por parte dos mesmos.

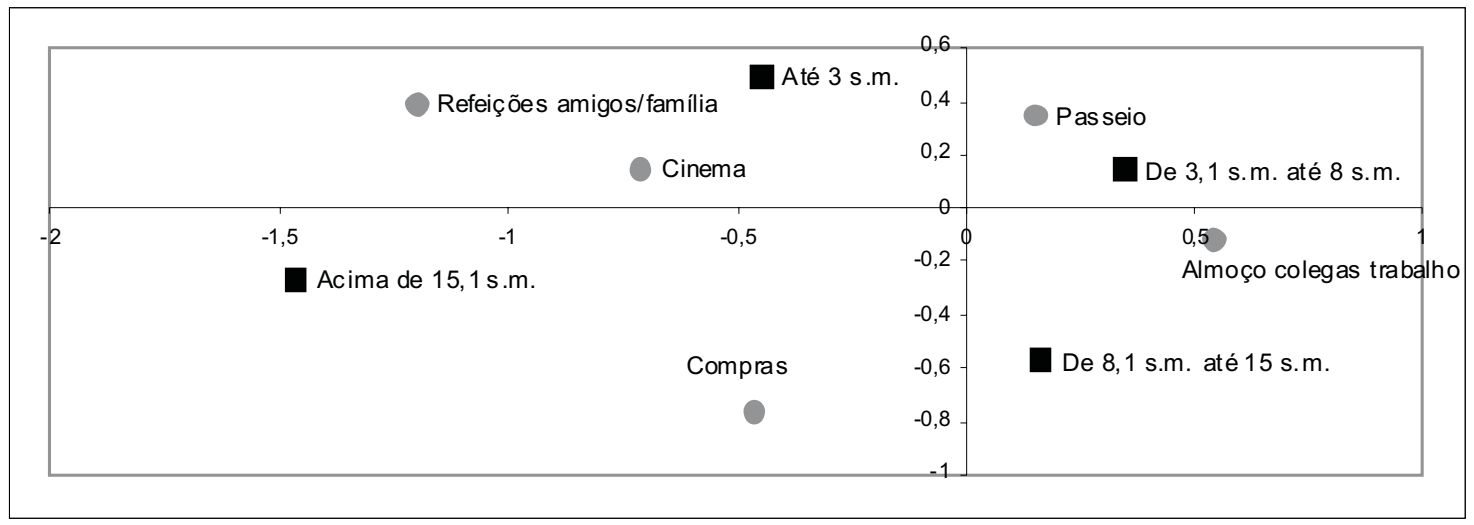

Figura 3 - Motivo para ida ao shopping center nos dias úteis por renda familiar.

A aplicação da técnica de análise de correspondência é possível, pois o contingenciamento entre a faixa etária e o motivo de ida ao shopping nos dias úteis mostra que essas variáveis não são independentes $\left(x^{2}=28,284 ; p=0,000\right)$, ou seja, não se combinam aleatoriamente (Tabela 6).

Tabela 6 - Tabela de contingência entre faixa etária e motivos de ida ao shopping center durante a semana

\begin{tabular}{l|c|l|l|c|c|c}
\hline Renda Familiar & Cinema & Passeio & $\begin{array}{l}\text { Almoço colegas } \\
\text { trabalho }\end{array}$ & $\begin{array}{l}\text { Almoço } \\
\text { amigos/família }\end{array}$ & Compras & Total \\
\hline Até 24 anos & 19 & 39 & 22 & 3 & 8 & 91 \\
\hline De 25 a 40 anos & 24 & 35 & 76 & 11 & 22 & 168 \\
\hline De 41 a 60 anos & 7 & 27 & 23 & 4 & 16 & 77 \\
\hline Total & 50 & 101 & 121 & 18 & 46 & 336 \\
\hline
\end{tabular}

Rev. Adm. UFSM, Santa Maria, v. 2, n. 1, p. 130-146, jan./abr. 2009 
Considerando a segmentação dos respondentes por faixa etária, as diferenças entre os segmentos de respondentes é mais marcante (Figura 4). Enquanto o grupo de indivíduos até 24 anos apresentou maior proximidade aos motivos ir ao cinema e passear, para o grupo com idade entre de 41 anos e 60 anos, a realização de compras destaca-se entre os demais motivos. Para o outro grupo (entre 25 anos e 40 anos), o almoço com colegas de trabalhos foi a opção mais citada.

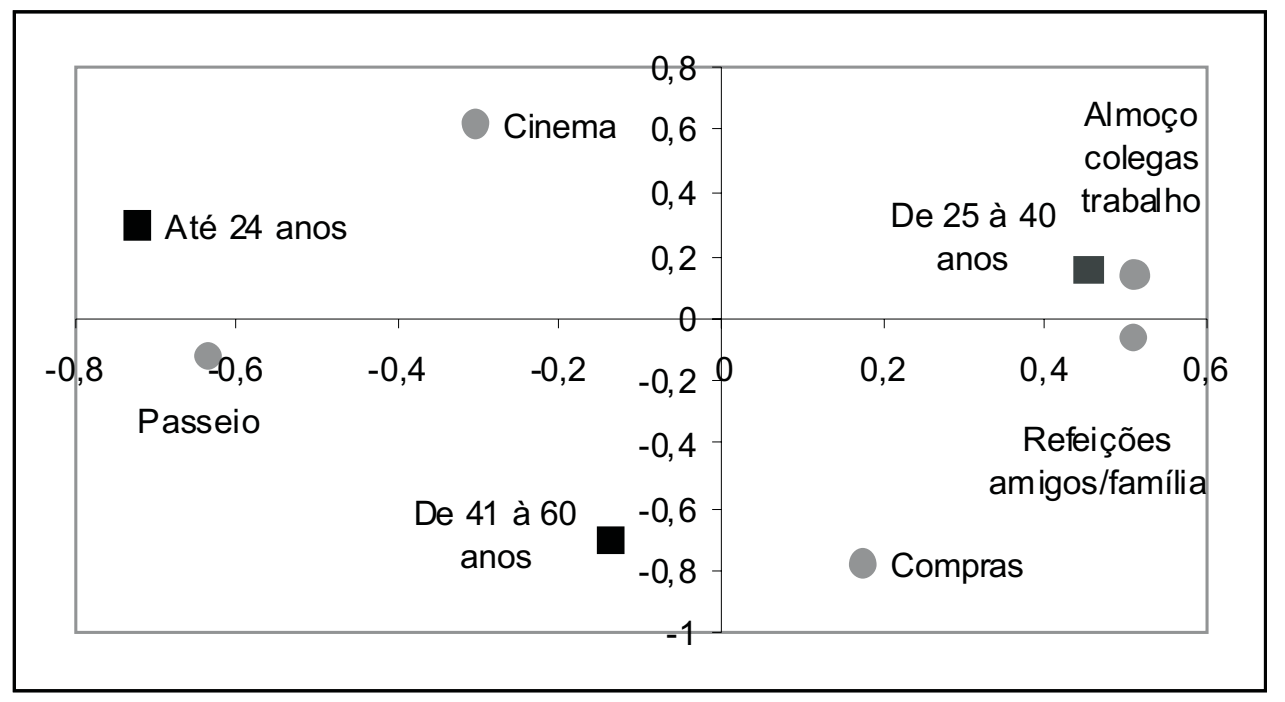

Figura 4 - Motivo para ida ao shopping center nos dias úteis por faixa etária.

A aplicação da técnica de Análise de Correspondência também foi efetuada sobre o principal motivo mencionado por cada respondente para frequentar o shopping center aos finais de semana. A fim de facilitar a interpretação dos resultados no mapa perceptual, apenas os cinco motivos mais citados pelos respondentes foram considerados, incluindo um total de 429 respostas $(85,8 \%$ do total da amostra).

Nesse caso, o contingenciamento entre o grupo socioeconômico e o motivo de ida ao shopping aos finais de semana indica que essas variáveis não são independentes ( $\chi^{2}=78,793$; $p=0,000$ ), ou seja, não se combinam aleatoriamente, permitindo a aplicação da técnica de análise de correspondência (Tabela 7).

Tabela 7 - Tabela de contingência entre grupo e motivos de ida ao shopping center aos finais de semana

\begin{tabular}{|c|c|c|c|c|c|c|}
\hline$\overline{\text { Grupo }}$ & $\overline{\text { Cinema }}$ & Pas seio & $\begin{array}{l}\text { Encontro com } \\
\text { amigos }\end{array}$ & Compras & Namorar & Total \\
\hline Grupo I & 45 & 62 & 3 & 13 & 6 & 129 \\
\hline Grupo II & 19 & 21 & 11 & 20 & 17 & 88 \\
\hline Grupo III & 14 & 25 & 2 & 27 & 10 & 78 \\
\hline Grupo IV & 38 & 24 & 3 & 14 & 3 & 82 \\
\hline Grupo V & 23 & 13 & 6 & 9 & 1 & 52 \\
\hline Total & 139 & 145 & 25 & 83 & 37 & 429 \\
\hline & $\chi^{2}: 78,7$ & & \multicolumn{2}{|c|}{ GL:16 } & \multicolumn{2}{|c|}{ p: 0,000} \\
\hline
\end{tabular}

A análise por grupo de distritos municipais revelou, para a frequência nos finais de semana, uma distribuição clara dos motivos de compras (Figura 5). Para os respondentes do 
grupo I, a principal razão de ida ao shopping citada foi passear. Já para os integrantes dos grupos IV e V, compostos de distritos com maior poder aquisitivo, destacou-se a ida ao cinema como motivo principal. Para o grupo II, o shopping center é associado a um local para namorar. A realização de compras destacou-se apenas para os indivíduos do grupo III. A comparação desses resultados com os motivos apresentados para a frequência durante a semana (de segunda a sexta-feira) revela uma mudança no papel do shopping aos finais de semana. Nesse período, cresce a importância das opções associadas ao lazer, quando o shopping center é associado a um local para passear, para namorar e para ir ao cinema.

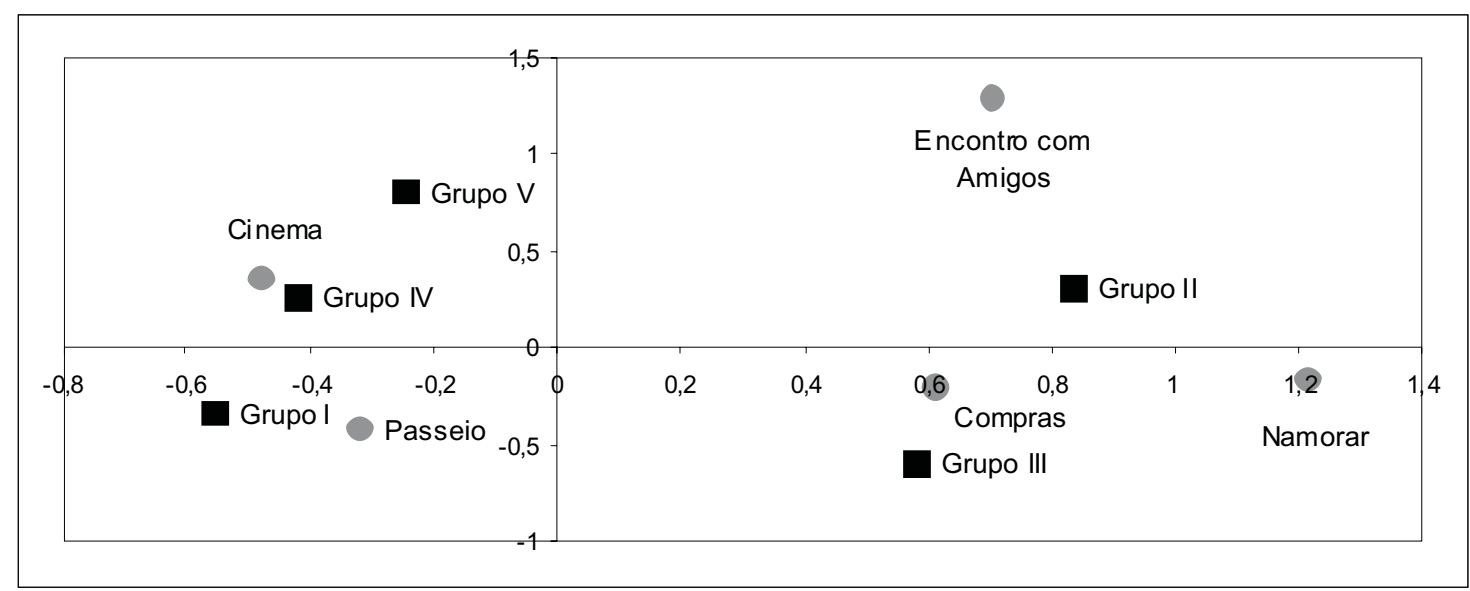

Figura 5 - Motivo para ida ao shopping center nos finais de semana por grupo.

O contingenciamento entre a renda familiar e o motivo de ida ao shopping aos finais de semana mostra que estas variáveis não são independentes $\left(x^{2}=24,652 ; p=0,017\right)$, ou seja, não se combinam aleatoriamente, possibilitando a aplicação da técnica de análise de correspondência.

Tabela 8 - Tabela de contingência entre renda familiar e motivos de ida ao shopping center aos finais de semana

\begin{tabular}{|c|c|c|c|c|c|c|}
\hline Renda Familiar & Cinema & Passeio & $\begin{array}{l}\text { Encontro com } \\
\text { Amigos }\end{array}$ & Compras & Namorar & Total \\
\hline Até 3 s.m. & 20 & 36 & 7 & 11 & 10 & 84 \\
\hline De 3,1 s.m. até 8 s.m. & 71 & 71 & 15 & 31 & 18 & 206 \\
\hline De 8,1 s.m. até 15 s.m. & 36 & 28 & 2 & 31 & 8 & 105 \\
\hline Acima de 15,1 s.m. & 12 & 10 & 1 & 10 & 1 & 34 \\
\hline Total & 139 & 145 & 25 & 83 & 37 & 429 \\
\hline \multicolumn{2}{|c|}{$X^{2}: 24,652$} & \multicolumn{2}{|r|}{ GL:12 } & \multicolumn{3}{|c|}{ p: 0,017} \\
\hline
\end{tabular}

Considerando a amostra agrupada por faixa de renda, identificou-se uma grande proximidade dos motivos cinema, namoro e passeio aos respondentes com renda familiar entre 3,1 e 8 salários mínimos. O motivo compras, por sua vez, apresenta-se localizado entre os grupos com maior poder aquisitivo (Figura 6). 


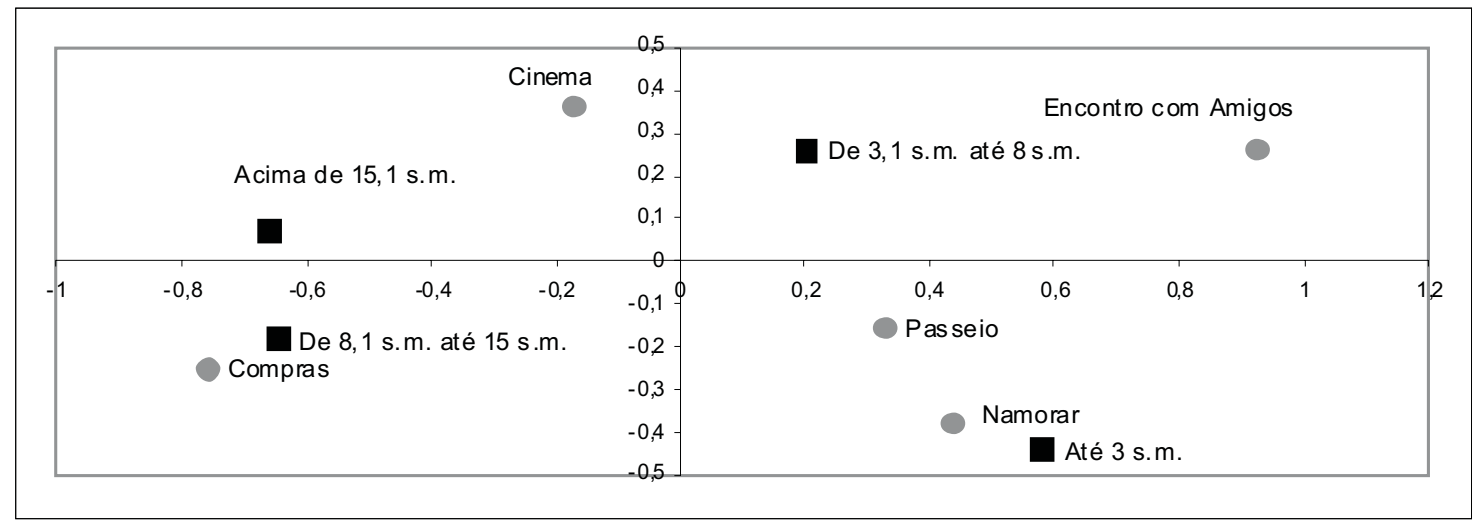
familiar.

Figura 6 - Motivo para ida ao shopping center nos finais de semana por renda

A aplicação da técnica de análise de correspondência é possível, uma vez que o contingenciamento entre a faixa etária e o motivo de ida ao shopping aos finais de semana revela que estas variáveis não são independentes $\left(x^{2}=64,938 ; p=0,000\right)$, ou seja, não se combinam aleatoriamente.

Tabela 9 - Tabela de contingência entre faixa etária e motivos de ida ao shopping center aos finais de semana

\begin{tabular}{|c|c|c|c|c|c|c|}
\hline Renda Familiar & Cinema & Passeio & $\begin{array}{l}\text { Encontro com } \\
\text { amigos }\end{array}$ & Compras & Namorar & Total \\
\hline Até 24 anos & 40 & 30 & 14 & 11 & 27 & 122 \\
\hline De 25 a 40 anos & 61 & 78 & 11 & 46 & 9 & 205 \\
\hline De 41 a 60 anos & 38 & 37 & 0 & 26 & 1 & 102 \\
\hline Total & 139 & 145 & 25 & 83 & 37 & 429 \\
\hline \multicolumn{2}{|c|}{$\frac{1}{\chi^{2}: 64,938}$} & & \multicolumn{2}{|c|}{ GL:8 } & \multicolumn{2}{|c|}{ p: 0,000} \\
\hline
\end{tabular}

Ao segmentar o grupo de respondentes por faixa etária, identificou-se que o motivo namoro aproxima-se do grupo com idade até 24 anos, enquanto as compras estão mais associadas à faixa etária de 25 a 40 anos. As opções ir ao cinema, passear e almoçar aparecem localizadas entre os três grupos de respondentes.

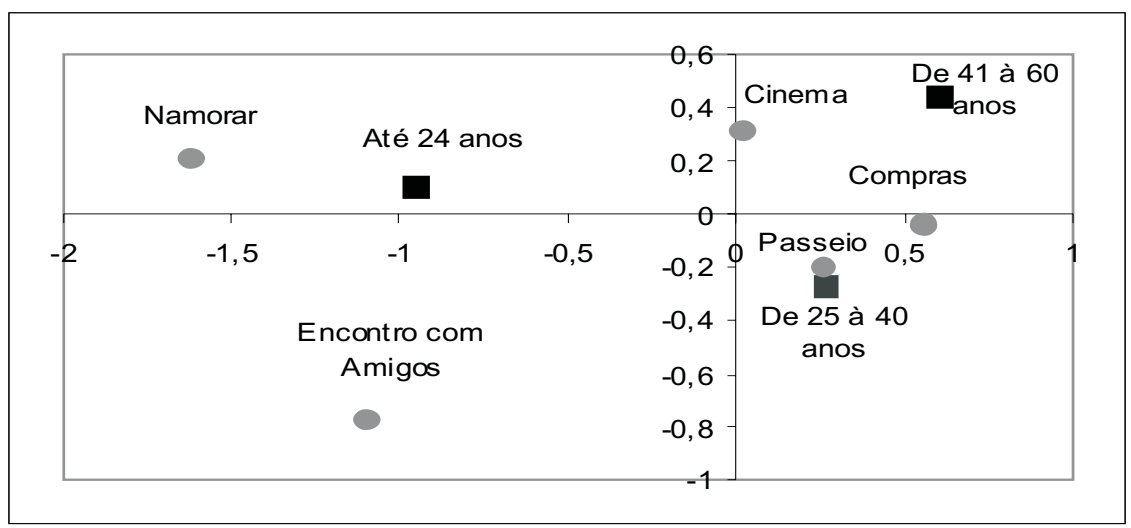

Figura 7 - Motivo para ida ao shopping center nos finais de semana por faixa etária. 
A associação entre o principal motivo para frequentar o shopping center e os segmentos de respondentes apurados a partir dos critérios grupos de distritos, faixa de renda e faixa etária revelou alguns aspectos que merecem ser destacados. Primeiro, durante a semana (dias úteis) o shopping center é associado, principalmente, a um local para almoçar com colegas de trabalho e para a realização de compras. Durante os finais de semana, ele assume uma função diferenciada, sendo identificado como local para lazer. Comparando as respostas dadas pelos mesmos grupos de respondentes para os dias úteis e os finais de semana, verifica-se claramente essas mudanças.

Além disso, as diferenças identificadas entre os dados levantados juntos aos diferentes segmentos para o mesmo período revelam a importância de considerar os aspectos localização, renda e idade para entender as motivações das pessoas para frequentar esse tipo de empreendimento.

\section{Conclusões}

Este trabalho analisou a motivação do consumidor para ir ao shopping center, revelando diferenças expressivas entre diferentes grupos de frequentadores desses centros comerciais.

Os resultados sinalizaram que, para a amostra entrevistada, o shopping center é mais do que um simples local para realização de compras, os resultados do trabalho permitem classificar o público segundo os dias da semana, mais especificamente: dias úteis e finais de semana. A aplicação da técnica de análise de correspondência, considerando o principal motivo para frequentar os shopping centers, revelou diferenças entre esses dois períodos e entre os diferentes segmentos de consumidores.

A extrapolação dos resultados deste estudo para a população adulta do município de São Paulo está limitada pelas características do método de amostragem por quotas e do método de levantamento de dados. Por exemplo, alguns grupos, como o público de renda alta ("AAA"), dificilmente são acessíveis a entrevistas realizadas na rua.

A investigação mais profunda dessas diferenças pode permitir um conhecimento melhor dos interesses de cada público. Desse modo, a realização de uma pesquisa que investigue as demais etapas do processo de escolha do local de compra pode contribuir para um maior conhecimento sobre o frequentador de shopping centers e para a definição de estratégias de posicionamento por parte dos gestores desses empreendimentos.

\section{Referências}

ABRASCE. Associação Brasileira de Shopping Centers. Disponível em: <http://www.abrasce. com.br/>. Acesso em: 01 jun. 2006.

ALSHOP. Associação Brasileira de Lojistas de Shopping. Disponível em: <http://www.alshop. com.br/>. Acesso em: 01 jun. 2006.

\section{ATLAS AMBIENTAL DO MUNICÍPIO DE SÃO}

PAULO. Disponível em: <http://atlasambiental. prefeitura.sp.gov.br>. Acesso em: 14 jun. 2006.

BAKER, Julie et al. The influence of multiple store environment cues on perceived merchandise 
value and patronage intentions. Journal of Marketing, Chicago, v. 66, n. 2, p. 120-142, Apr. 2002.

BELL, D.R., HO, T-K.; TANG, C.S. Determining where to shop: fixed and variable costs of shopping. Journal of Marketing Research, $p$. 352-369, Aug. 1998.

BERMAN, Barry; EVANS, Joel. Retail

management: a strategic approach. 7. ed. New Jersey: Prentice Hall, 1998.

BRANCO, Carlos Eduardo Castello; GORINI, Ana Paula Fontenelle; MENDES, Eduardo da Fonseca; PIMENTEL, Marcos de Oliveira. Setor de Shopping Center no Brasil: Evolução Recente e Perspectivas. BNDES Setorial, Set. 2007.

Disponível em: <http://www.bndes.gov.br/ conhecimento/resposta.asp?setorTema $=$ Com $\%$ E9 rcio+e+Servi\%E7os>. Acesso em: 01 jul. 2008.

BNDES. Shopping Center. Relatos Setoriais. 1996. Disponível em: <http://www.bndes.gov.

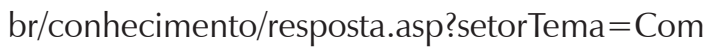
\%E9rcio+e+Servi\%E7os>. Acesso em: 14 jun. 2006.

ENGEL, James F.; BLACKWELL, Roger D.; MINIARD, Paul W. Comportamento do Consumidor. 8. ed. Rio de Janeiro: LTC, 2000.

HAIR, J.F.; ANDERSON, R.E.; TATHAM, R.L.; BLACK, W. C. Análise multivariada de dados.

Trad. Adonai Schlup Sant'Anna e Anselmo Chaves Neto. 5. ed. Porto Alegre: Bookman, 2005.

IHU. A Privatização do Lazer: Entrevista com Ricardo Freitas. IHU On-line. São Leopoldo, p. 7-9 15/agosto/2005. Disponível em: <http://www.unisinos.br/ihu_online/uploads/ edicoes/1158345183.1pdf.pdf > . Acesso em: 01 jun. 2006.

KOTLER, Philip. Atmospherics as a marketing tool. Journal of Retailing, v. 49, Winter,1974. p. 48-64.

KOTLER, Philip \& ARMSTRONG, Gary.

Princípios de marketing. 7. ed. Rio de Janeiro: LTC, 1999.
LEE, Sim Loo; IBRAHIM, Muhammad Faishal; HSUEH-SHAN, Chong. Shopping-centre attributes affecting male shopping behaviour. Journal of Retail \& Leaisure Property, London, v. 4, n. 4, p. 324-341, Oct. 2005.

LEVY, Michel; WEITZ, Barton. Administração de varejo. São Paulo: Atlas, 2000.

LOJISTAS.NET. O portal do lojista em shopping center. Disponível em: < http://www.lojistas. net/>. Acesso em: 01 jun. 2006.

MARTIN, Craig A.; TURLEY, L.W. Malls and consumption motivation: an exploratory examination of older Generation $Y$ consumers.

International Journal of Retail \& Distribution Management, Bradford, v. 32, n. 10, p. 464, 2004.

MASON, J. Barry; MAYER, Morris L.;

WILKINSON, J.B. Modern retailing: theory and practice. 6. ed. Boston: IRWIN, 1993.

MASON, J. Barry; BURNS, David J. Retailing. 6. ed. Houston: Dame, 1998.

MOACYR, Gustavo Bueno. Shopping centers: atualidade brasileira da tendência mundial.

Boletim Técnico do Senac, v. 23, n. 2, maio/ ago.1997. Disponível em: < http://www.senac. br/conhecimento/bts.html>. Acesso em: 01 jun. 2006.

NICHOLLS, John A. F. Time and companionship: key factors in hispanic shopping behavior. The Journal of Consumer Marketing, Santa Barbara, v. 14, n. 3, p. 194, 1997.

SAMLI, A. Coskun. Retail marketing strategy: planning, implementation and control. Connecticut: Quorum, 1989.

SIT, Jason; MERRILEES, Bill; BIRCH, Dawn. Entertainment-seeking shopping center patrons: the missing segments. International Journal of Retail \& Distribution Management, Bradford, v. 31, n. 2/3, p. 80-95, 2003.

STOLTMAN, Jeffrey J.; MORGAN, Fred W., ANGLIN, Linda K. An investigation of retail shopping situations. International Journal of Retail \& Distribution Management, Bradford, v. 27, n. 4, p. 145, 1999. 
YAVAS, Ugur. A multi-attribute approach to understanding shopper segments. International Journal of Retail \& Distribution Management, Bradford, v. 31, n. 11-12, p. 541-549, 2003.

WONG, Grace Khei Mie; LU, Yu;YUAN, Lim Lan SCATTR: an instrument for measuring shopping centre attractiveness. International Journal of Retail \& Distribution Management, v. 29, n. 2, p. 76-86, 2001. 